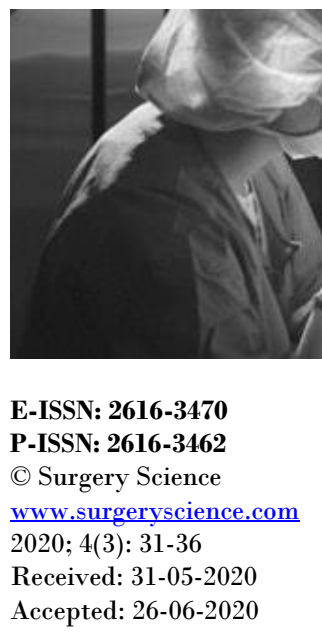

Dr. ASM Anwarul Kabir

Registrar, Surgery department. Holy family Red Crescent medical College and Hospital, Dhaka, Bangladesh

Dr. Mohammad Ashik Anwar Bahar Sylhet MAG Osmani Medical College, Sylhet, Associate Professor, Surgery Department, Bangladesh

Dr. Muhammad Faridul Haque Assistant Professor, Surgery department. Sylhet MAG Osmani Medical College, Sylhet, Bangladesh

Dr. MA Osman Farooqui

Assistant Professor, Surgery

Department. Sylhet MAG Osmani

Medical College, Sylhet, Bangladesh

Dr. Md. Babul Akter

Assistant Professor, Surgery

Department. Sylhet MAG Osmani

Medical College, Sylhet, Bangladesh

Mahbuba Sharmin

Medical officer, Bangabandhu Sheikh Mujib Medical University (BSMMU),

Dhaka, Bangladesh

\section{Khaleda Akhter}

Registrar, Holy family Red Crescent medical College and Hospital, Dhaka, Bangladesh

Dr. Mohammad Shahidul Alam Professor. Department of Botany Rajshahi University, Rajshahi, Bangladesh

Imtiaz Ahmad

Professor, Surgery department. Holy family Red Crescent medical College and Hospital, Dhaka, Bangladesh

Corresponding Author: Dr. ASM Anwarul Kabir Registrar, Surgery department. Holy family Red Crescent medical College and Hospital, Dhaka, Bangladesh

\section{International Journal of Surgery Science}

\author{
Dr. ASM Anwarul Kabir, Dr. Mohammad Ashik Anwar Bahar, Dr. \\ Muhammad Faridul Haque, Dr. MA Osman Farooqui, Dr. Md. Babul \\ Akter, Mahbuba Sharmin, Khaleda Akhter, Dr. Mohammad Shahidul \\ Alam and Imtiaz Ahmad
}

DOI: https://doi.org/10.33545/surgery.2020.v4.i3a.467

\section{Abstract}

Background: Inguinal hernia repair is a commonly performed general surgical procedure that constitute more than $95 \%$ of all groin hernia repairs. However, in developing countries, quite a considerable percentage of it is not repaired or delayed repaired and that lead to a higher incidence of morbidity and mortality. so, we planned to conduct this study to understand the clinic-epidemiologic profile of inguinal hernia in a tertiary care hospital of Bangladesh.

Objective: To evaluate the clinical, epidemiological profile and associated risk factors for inguinal hernia. Methodology: This observational study was conducted among 100 patients during January 2018 to January 2019 who admitted in the surgery department of a tertiary care center for inguinal hernia surgery . All the study subjects were examined and their clinical and epidemiological profiles studied, tabulated and analyzed.

Result: Among the 100 patients, most of them (94\%) were men with a age of $57.02 \pm 12.87$, farmer (36\%) by occupation. $61 \%$ patients were in low saocio-ecenomic status. Most of the patients $(60 \%)$ were in the age group of 40-60 years followed by less than 30 years $(21 \%)$. On query regarding symptoms of inguinal hernia, all of them $(100 \%)$ complaints of groin swelling. More than half of the patients complaints of groin pain and sensation of heaviness in groin. On clinical examination, right sided, left sided, bilateral hernias were found in $49 \%, 45 \%$ and $6 \%$ study patients respectively. Direct hernias, indirect, pantaloons hernias were seen in $57 \%, 30 \%, 7 \%$ study patient respectly. Most of hernias $(81 \%)$ were reducible and were incomplete $(88 \%)$. Most of the patients $(75 \%)$ presented late to the health care center due to the lack of awareness of the disease and were initially treated by homeopath medicine. During query about risk factors for inguinal hernia, $46 \%$ patients were more than 50 years of age and $26 \%$ patients were smoker. In this study, most common hernia repair procedure was Lichtenstein's procedure $(63 \%)$ followed by modified Bassini's procedure (11\%). Total open procedure were $93 \%$ and laparoscopic hernia repairs were done only in $7 \%$ patients.

Keywords: Inguinal hernia, epidemiology, risk factors

\section{Introduction}

Hernia is a Latin term that is defined as an "abnormal protrusion of a viscus or part of a viscus through a normal or abnormal opening in the wall of its containing cavity". 1Still now nguinal hernia repair is second most common general surgical operations worldwide that account for about $10-15 \%$ of all surgical procedures ${ }^{[7,17]}$. It is very common in men with lifetime risk of $27 \%$ and $3 \%$ for women, thus 1 in 4 men has the risk of developing the condition. and incidence increase with increase of age in man ${ }^{[2,7]}$ Though exact data of hernia surgery in Bangladesh is unavailable, but with the average global incidence of hernia surgery being 3 per 1000 population yearly ${ }^{[4]}$, Bangladesh with a population of 180 million where more than half million hernia surgeries performed every year. Very often hernia as a disease is ignored specially underdeveloped and developing countries as they may remain asymptomatic for prolonged periods, the severity of the condition is often overlooked and ultimately it results higher mortality as high as $7 \%$ in emergency surgeries $[1,7,17]$

World health organization (2002) reported that inguinal hernias are sources of social stigma ${ }^{[4,7]}$. 
It lower the chances for employment, create sexual problems, physical deformation, loss of work, low self-esteem or confidence ${ }^{[3,5,7]}$ People who are living with victims of inguinal hernia were reported to have not only poor health-seeking behavior but also they were negligent about their conditions, ignorant about the life threatening side effects or complications associated with their conditions. Sometimes cultural, educational factors and economic constraints may prevent the realization of illness and suppress proper utilization of available health services. So, in developing countries, quite a considerable percentage of inguinal hernia is not repaired that leads to a higher incidence of morbidity and mortality.

Inguinal hernias may be congenital or acquired [7] Several hypotheses regarding the etiology of inguinal hernia have been proposed. In male increased abdominal pressure, preexisting abdominal muscles weakness, constipation, prostatism, chronic cough, heavy weight lifting,

obesity, smoking, aging, pelvic fractures and trauma, connective tissue diseases, and systemic illnesses and in females, obesity, pregnancy, and operative procedures have been proposed and well-known risk factors that commonly contribute to the formation of inguinal hernia.

In Bangladesh, there is insufficient published data on the clinical and epidemiological

profile of patients presenting with inguinal hernia and this study may provide further understanding to the pathophysiology of inguinal hernia development and may estimate the prevalence, age and gender differences, risk factors associated with the inguinal hernia development. Available data may increase the awareness and knowledge of health care proider regarding inguinal hernia and may help to reduce the burden of hernia in Bangladesh.

\section{Material and methods}

During january 2018 to January 2019, this prospective study was conducted among 100 patient who were clinically diagnosed as primary inguinal hernia and admitted in the surgery department of Holy Family Red Crescent Medical College Hospital, Dhaka for surgery. Necessary particulars regarding relevant history, demographic facts, risk factors, clinical data and examination findings, operation theatre logs data were recorded in a questionnaire, then, tabulated and analysed by SPSS (version 24.0) software. Statistical methods were used in data analysis, yielding quantitative results. Outcome of surgery was not a parameter of assessment.

\subsection{Inclusion criteria}

- Patients`s age $>18$ years having primary inguinal hernia.

- Only elective cases were included.

Those who willingly gave informed consent.

\subsection{Exclusion criteria}

- Patient`s age $<18$ years.

- Recurrent hernias.

- Patients previously operated for contralateral inguinal hernia.

- History of surgery for any groin or ventral hernia in the past.

- Patients being simultaneously operated for coexisting other surgical conditions including ventral hernias were excluded.

Ethical approval was obtained from the Institutional Ethic Review Committee before the commencement of the study. A well informed written consent was taken from each patient prior to being enrolled into this study.

\section{Results}

Total 100 patients were enrolled in this study, mean age was $57.5 \pm 11.26$ years and the majority $(60 \%)$ patients belonged to the 40-60 years. Increasing incidence noted in early age and in old age (Figure 1). Among 100 patients, 94 were male and only 6 patient were female (Figure 2).

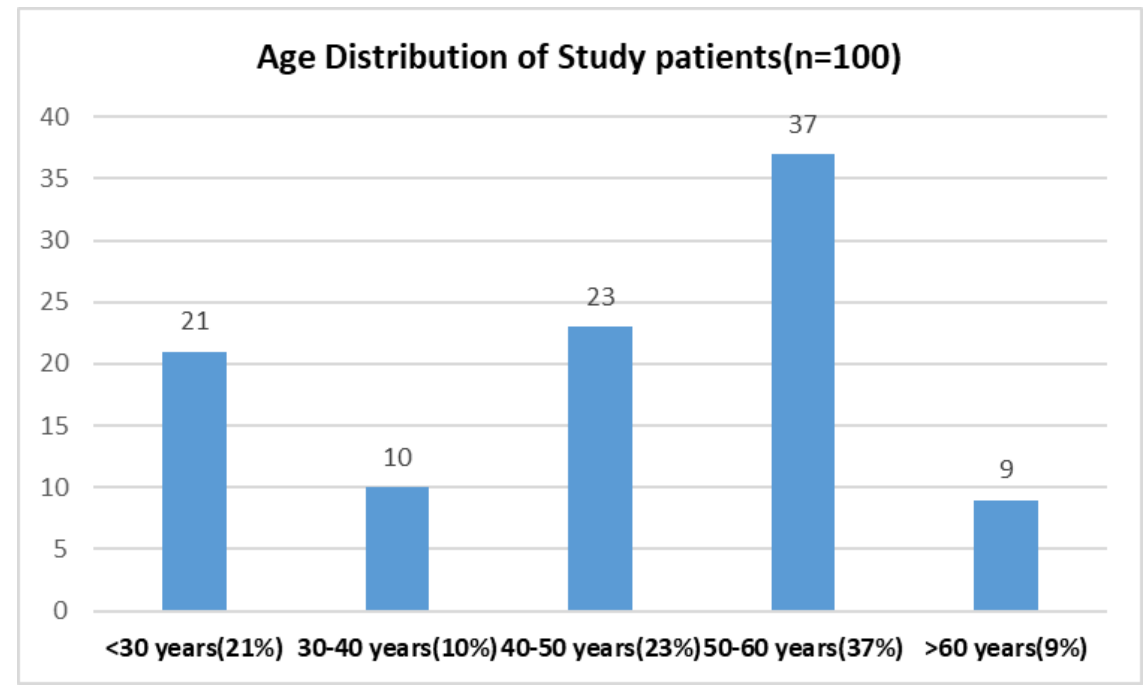

Fig 1: Bar diagram showing the age of the study patients. 


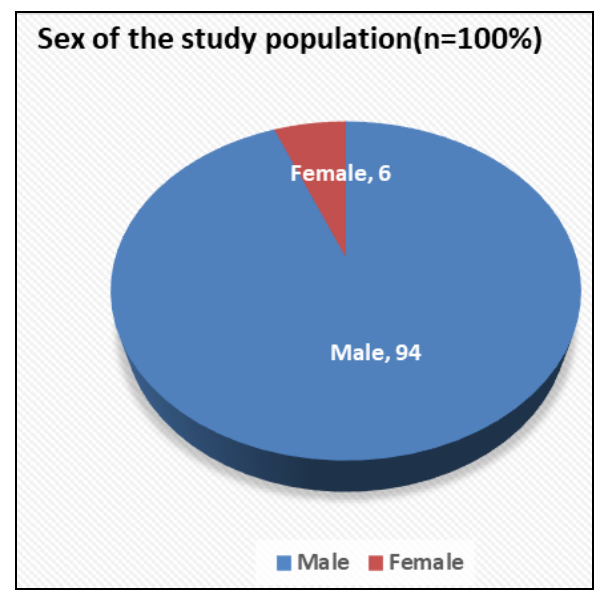

Fig 2: Pie diagram showing the sex of the study patients.

leading profession was cultivation (36\%), while $23 \%$ the patients were servicemen. Business was profession for about
$13 \%$ patients. Labor and student were other notable profession. (Figure 3)

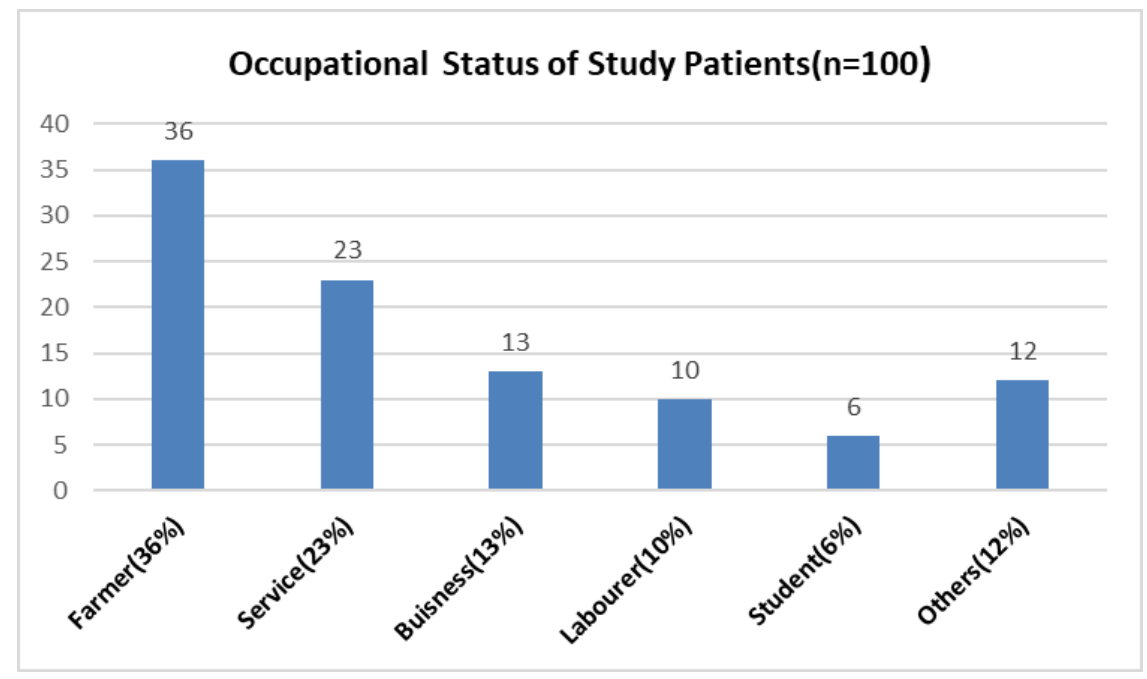

Fig 3: Bar diagram showing the occupational status of the study patients.

In this study, $61 \%$ patients were in low saocio-ecenomic status, catagories respectively (figure 4). $24 \%$ and $15 \%$ were in middle and higher socio-ecenomic

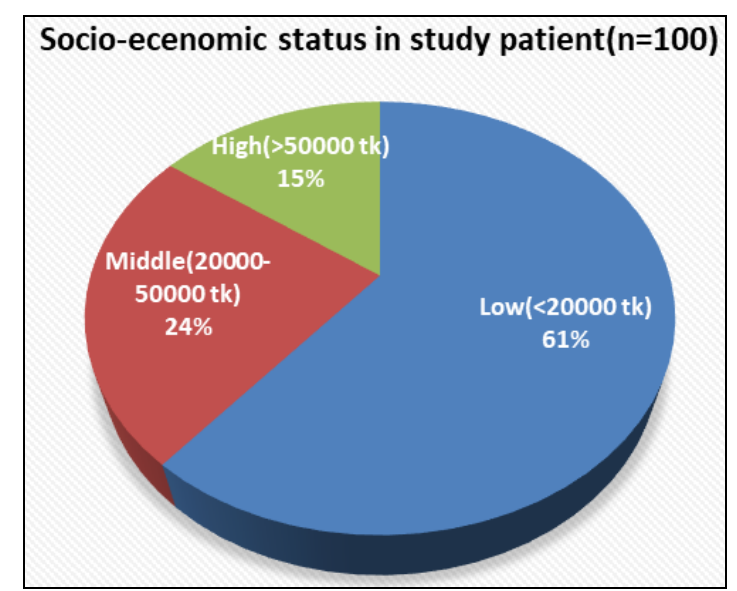

Fig 4: Bar diagram showing socio-ecenomic status in patinets.

On query, regarding symptoms of inguinal hernia, all of them $(100 \%)$ complaints of groin swelling. Groin pain, sensation of heaviness in groin, burning sensation in groin, swelling in scrotum, features of obstruction features of strangulation noted in $64 \%, 62,57 \%, 29 \%, 7 \%, 4 \%$ respectively. (Figure 5) 


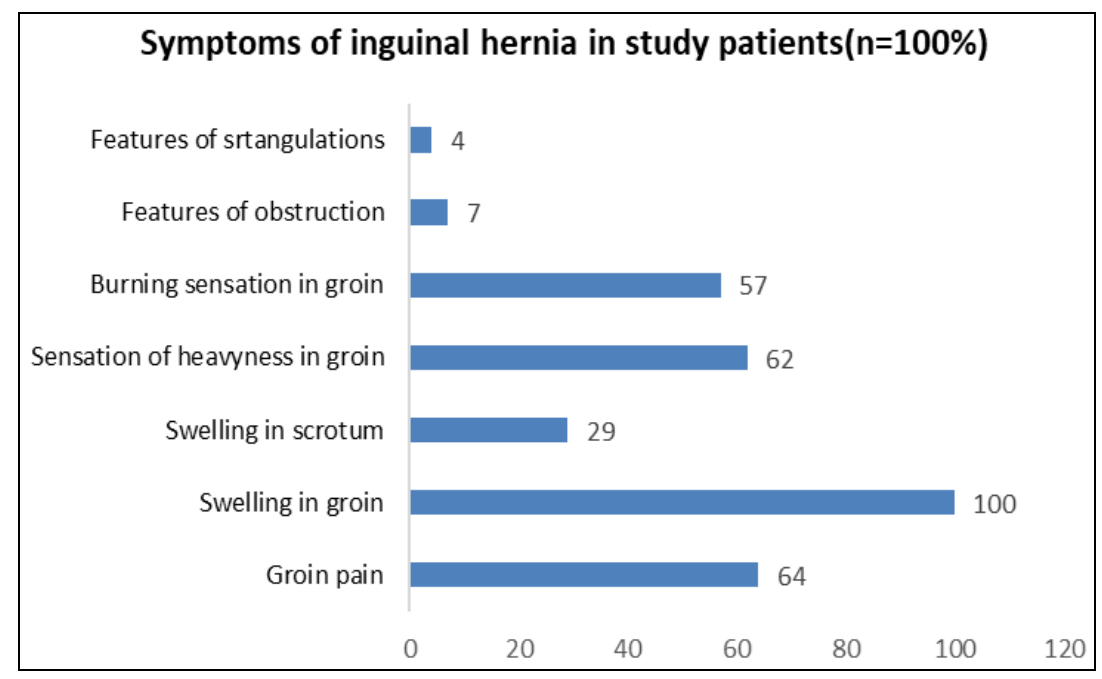

Fig 5: Bar diagram showing distribution of various symptoms observed in patinets.

Among 100 study patients in 41 patients duration of symptoms were more than 12 months. Mean duration $8.03 \pm 8.15$ months (Table 1)

Table 1: Duration of symptoms in the study populations.

\begin{tabular}{|c|c|c|}
\hline Duration of swelling & No of patients & Percentage (\%) \\
\hline $0-3$ months & 28 & $28 \%$ \\
\hline $3-6$ months & 13 & $13 \%$ \\
\hline 6-12 months & 18 & $18 \%$ \\
\hline$>12$ months & 41 & $41 \%$ \\
\hline
\end{tabular}

\begin{tabular}{|c|c|c|}
\hline Total & 100 & $100 \%$ \\
\hline Mean duration & $8.03 \pm 8.15$ & \\
\hline
\end{tabular}

Most of the patients (41\%) presented late to the hospital due to lack of awareness of the disease.

$24 \%$ patients had financial constraints. $34 \%, 19 \%$ reated by treated by homeopath medicine and traditional healer respectively. $23 \%$ relactant to treatment due to fear of surgery. (Table 2)

Table 2: Reasons for late presentation to health care centte.

\begin{tabular}{|c|c|c|}
\hline $\begin{array}{c}\text { Reasons for late presentation (the percentages will not add up to } 100 \\
\text { as each patient had multiple reasons) }\end{array}$ & No of patients $(n=100)$ & Percentage $(\%)$ \\
\hline \multicolumn{3}{|l|}{$\begin{array}{ll} & \text { Financial constrains } \\
\end{array}$} \\
\hline Present & 24 & $24 \%$ \\
\hline \multicolumn{3}{|c|}{ Lack of awareness of disease } \\
\hline present & 41 & $41 \%$ \\
\hline \multicolumn{3}{|c|}{ Fear of surgery } \\
\hline present & 23 & $23 \%$ \\
\hline \multicolumn{3}{|c|}{ Long distance from health care facilities } \\
\hline Present & 17 & $17 \%$ \\
\hline \multicolumn{3}{|c|}{ Treated by traditional healer } \\
\hline Present & 19 & $19 \%$ \\
\hline \multicolumn{3}{|c|}{ Treated by homeopath medicine } \\
\hline present & 34 & $34 \%$ \\
\hline \multicolumn{3}{|c|}{ No reasons reported } \\
\hline present & 9 & $9 \%$ \\
\hline \multicolumn{3}{|l|}{ Others } \\
\hline Present & 7 & $7 \%$ \\
\hline
\end{tabular}

On clinical examination, right sided, left sided, bilateral hernias were found in $49 \%, 45 \%$ and $6 \%$ study patients respectively. Direct hernias, indirect pantaloons hernias seen were in $57 \%$, $30 \%, 7 \%$ study patient respectly. $81 \%$ hernia was reducible and $88 \%$ was incomplete (Table 3 ).

Table 3: Clinical examination in our study population.

\begin{tabular}{|c|c|c|}
\hline Type of Hernia & No of Patients(n=100) & Percentage (\% \\
\hline Right direct & 33 & $31 \%$ \\
\hline Right indirect & 11 & $11 \%$ \\
\hline Right pantaloon & 5 & $05 \%$ \\
\hline Left direct & 24 & $26 \%$ \\
\hline Left indirect & 19 & $19 \%$ \\
\hline Left Pantaloon & 2 & $02 \%$ \\
\hline
\end{tabular}

\begin{tabular}{|c|c|c|}
\hline Bilateral & 6 & $06 \%$ \\
\hline Total & 100 & $100 \%$ \\
\hline Reducibility & No of patients & Percentage (\%) \\
\hline Reducible & 81 & $81 \%$ \\
\hline Irreducuble & 19 & $19 \%$ \\
\hline Total & 100 & $100 \%$ \\
\hline Complete or incomplete & No of patients & Percentage (\%) \\
\hline Complete & 22 & $22 \%$ \\
\hline Incomplete & 88 & $88 \%$ \\
\hline Total & 100 & $100 \%$ \\
\hline
\end{tabular}

During query about risk factors for inguinal hernia,46\% patients were more than 50 years. $26 \%$ patients were smoker. History of prostatism, 1 ifting heavy weights lifting, constipation, obesity, chronic cough were seen in 19\%, 21\%, $17 \%, 7 \%, 7 \%$ study 
patients respectively. (Figure 6).

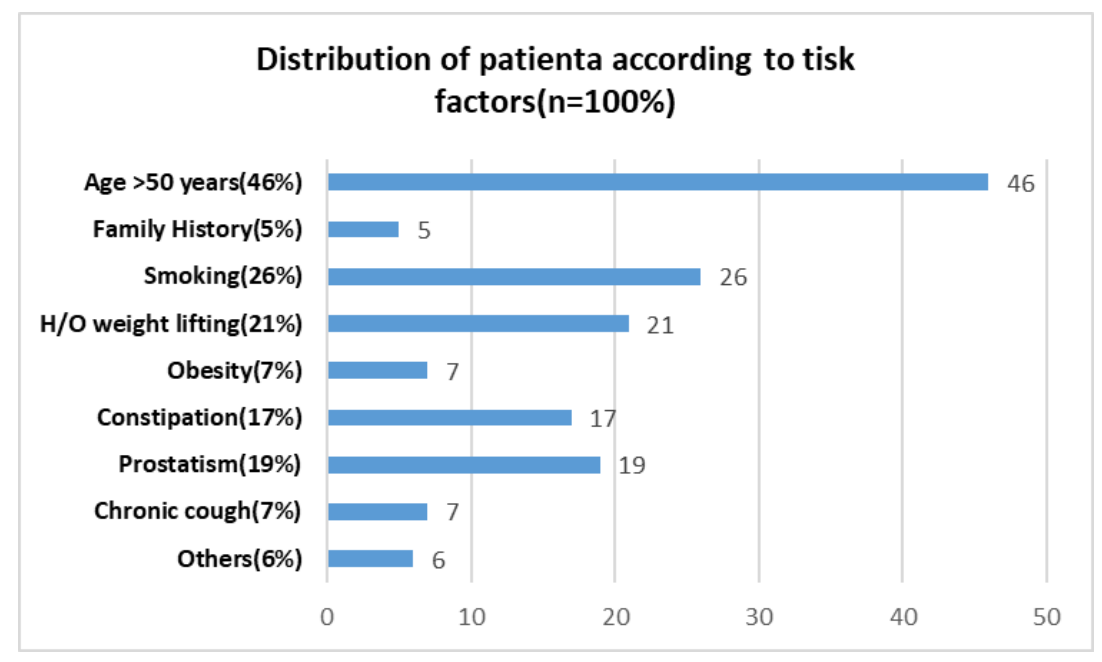

Fig 6: Bar diagram showing distribution of patients according to risk factors present.

Most common hernia repair procedure were Lichtenstein's procedure in $(63 \%)$ patients followed by modified Bassini's procedure in $11 \%$ patients. Total open procedure were $93 \%$ and laparoscopic hernia repairs were done only in 7 patients. (Table 4)

Table 4: Different surgical procedure done in study population.

\begin{tabular}{|c|c|c|}
\hline Operative procedure done & No of Patients (n=100\%) & Percentage (\%) \\
\hline Open procedure & & $93 \%$ \\
\hline Lichtenstein`s procedure & 63 & \\
\hline Modified Bassini’s procedure & 11 & \\
\hline Deserda repair & 3 & \\
\hline Meshplug repair & 5 & $7 \%$ \\
\hline Darn repair & 6 & $100 \%$ \\
\hline Shouldice repair & 5 & \\
\hline Laparoscopic procedure & 7 & \\
\hline Total & 100 & \\
\hline
\end{tabular}

\section{Discussion}

Among the 100 patients, most of them (94\%) were men with a mean age of $57.02 \pm 12.87$ years that coincides with other studies ${ }^{[4,8,11]}$ However, studying the distribution of age, most of the patients $(60 \%)$ in this study were in the age group of 40-60 years followed by less than 30 years (21\%).This type of bimodal peaking was found among the elderly and the young in some other studies also ${ }^{[4,6,8]}$ Due to increased incidence of inguinal hernia in this productive age group of 40-60 years, it becomes a burden on the economy of the country by increasing the morbidity.

Inguinal hernias are reported to be more common in low socioeconomic strata ${ }^{[2-4,7,12,15-19]}$. It is reflected very well in this study where most of the patients $(61 \%)$ were in low saocioecenomic status, $24 \%$ and $15 \%$ were in middle and higher socioecenomic catagories respectively.

In this study, right inguinal hernias were more common than left, ratio $1.08: 1$ and only $6 \%$ cases were bilateral which correlates with study done by Mukesh sangwan ${ }^{[8]}$ et al. showed 1.45:1 and with also some other studies $[7,5,17]$ In our study, direct hernias, indirect pantaloons hernias seen were in $57 \%$, $30 \%, 7 \%$ study patient respectly and the present study correlated well with Burcharth et al. ${ }^{[4]}$

In our study population, older age $(50 \%)$ and smoking (39\%) were the most common risk factors present. History of prostatism (19\%), heavy weightlifting $(21 \%)$, constipation(17\%) were the other common risk factors for the development of inguinal hernia in our study(Figure 5) that correlates with study of Robindera Kour et al. ${ }^{[10]}$ and some other studies ${ }^{3,5,7}$. Smoking was established as an independent risk factor for hernia development with Malviya et al. ${ }^{[1]}$ reporting $30.6 \% 10$ of their study. Family history however appears to be an independent risk factor in the etiopathogenesis ${ }^{[10,15,16]}$ but in this study only $5 \%$ study population had positive family history.

A study in USA conducted by Constance et al. ${ }^{[9]}$ found that the inguinal hernia was associated with older age, chronic cough, obesity, greater heigh, rural residence and it was supported by many other studies like Lau $\mathrm{H}$ et al. ${ }^{[6]}$ and Junge $\mathrm{K}$ et al. ${ }^{[5]}$, which showed that family history is an important predictor for development of inguinal hernias and as well as recurrent hernia. The other risk factors suggested were chronic cough, Prostatic hypertrophy, chronic constipation, Chronic Diabetes ${ }^{[7,14,16,17,19]}$ In this study, Lump (100\%) and pain (64\%) were the most common presenting symptoms that correlates with some other studies [2-3, 6-7, 10]. (Figure-4) Duration of symptoms at presentation in our study was 5.02 \pm 8.19 months and 59\% study patients presented to hospital after 6 months of their developing symptoms.(Table 3) In our study, most of the patients of inguinal hernia presented late to health care provider which is similar to the scenario in other developing countries $[8,11,12]$ Most of the patients (41\%) presented late to the hospital due to lack of awareness of the disease, $24 \%$ patients had financial constraints. $34 \%, 19 \%$ reated by treated by homeopath medicine and traditional healer respectively.23\% patient relactant to treatment due to fear of surgery. (Table 2)

During searching of operation theatre logs we recorded that open 
procedure were done in $93 \%$ patients and laparoscopic hernia repairs were done only in 7 patients among total 100 study patients. (Table 4) Among open procedure most common hernia repair procedure was Lichtenstein's procedure in $63 \%$ patients followed by modified Bassini's procedure in $11 \%$ patients compared to laparoscopic repair (7\%). It suggest that still Lichtenstein`s repair is till surgeon`s first choice in developing countries may be due to financial contrains.

\section{Conclusion}

In this study, we found that male are more affected than male. Right sided and direct hernia is more common. Most of the patients from low socio-ecenomic condition and main risk factors are old age, smoking, lifting heavy objects prostatism and constipation. lack of awareness of the disease, financial constraints, fear of surgery, treatement by homeopath medicine and traditional healer are common causes for late presentation to health care proiders that increase morbidity and mortality. Most common hernia repair procedure were Lichtenstein's procedure.

\section{Author's contribution}

Kabir ASMA: Eevaluation and optimization of all patients with comorbid conditions, script writer and compilation of results.

Sharmin M, Akhter K, Alam MS: Review of script and data entry, analysis.

SW: Data entry. RS, AAK: Evaluation and optimization of all patients with comorbid conditions.

MI: Data entry and review of article.

Alam MS, Ahmed, I Alam MS, Haque MF: Provided expert clinical opinion.

All authors edited and approved the manuscript prior to submission.

\section{Acknowledgements}

The authors are extremely grateful to the surgery department and also administration of Holy Family Red Crescent Medical College and Hospital for permitting this research and to the medical social workers for the help provided in conducting this study.

\section{Funding: No funding sources.}

\section{Conflict of interest}

The authors have no financial interests to disclose.

\section{Disclosures}

All authors have nothing to disclose.

\section{Ethical approval}

The study was approved by the Institutional Ethics Committee of Holy Family Red Crescent Medical College.

\section{References}

1. Malviya VK, Sainia TK, Parmar KK, Sharma S. Demographic study in operated patients with inguinal hernia. Surgical Update: Int J surg Orthopedics. 2019; 5:2026.

2. Ruhl CE, Everhart JE. Risk factors for inguinal hernia among adults in the US population. Am J Epidemiol. 2007; 165:1154-61.

3. Rutkow IM. Demographic and socioeconomic aspects of hernia repair in United States in 2003. Surgical Clinics of North America, 2003; 83:1045-1051.

4. Burcharth J, Pedersen M, Bisgaard T et al. Nationwide prevalence of groin hernia repair. PLoS One. 2013; 8:e54367.

5. Junge $\mathrm{K}$, Rosch $\mathrm{R}$, Klinge U, Schwab R, Peiper C, Binnebosel $\mathrm{M}$ et al. - Risk factors related to recurrence in inguinal hernia repair: a retrospective analysis. Hernia. 2006; 10:309-315.

6. Lau H, Fang C, Yuen WK, Patil NG. Risk factors for inguinal hernia in adult males: A case- control study. Surgery. 2007; 141:262-266.

7. Kabir ASMA, Ahmad I, Sharmin M, Akhter K, Hoq MR, Alam MS. Early outcome of Lichtenstein technique for complete variety of inguinal hernia repair in a tertiary care hospital. DOI: https://doi.org/10.3329/nimcj.v10i2.45435 Northern International Medical College Journal. 2019; 10(2):389-392.

8. Mukesh Sangwan1, Vijayata Sangwan, Mahender Garg, Parveen Mahendirutta, Uma Garg. Abdominal wall hernia in a rural population in India-Is spectrum changing? - Open journal of epidemiology. 2013; 3:135-138.

9. Constance E Ruhl, James E. Everhart. Risk Factors for Inguinal Hernia among Adults in the US Population. American journal of Epidemiology. Am J Epidemiol. 2007; 165(10):1154-1161.

10. Robindera Kour, Gurpreet Kour, Iqbal Singh, Bimla Bhagat, Dr. KK Gupta. Determining the clinic-demographic profile and associated risk factors of inguinal hernia: A prospective observational study.

DOI: https://doi.org/10.33545/surgery.2019.v3.i2c.377.

11. Ashwath Narayan Ramji. Anthropology of inguinal hernia. International Journal of Contemporary Medical Research. 2019; 6(5):E30-E34.

12. Rao SS, Singh P, Gupta D, Narang R. Clinicoepidemiologic profile of inguinal hernia in rural medical college in central India. J Mahatma Gandhi Inst Med Sci. 2016; 21:116-21.

13. Mabula JB, Chalya PL. Surgical management of inguinal hernias at Bugando Medical Centre in Northwestern Tanzania: Our experiences in a resource-limited setting. BMC Res Notes. 2012; 5:585.

14. Mabula JB, Chalya PL. Surgical management of inguinal hernias at Bugando Medical Centre in Northwestern Tanzania: Our experiences in a resource-limited setting. BMC Res Notes. 2012; 5:585.

15. Flich J, Alfonso JL, Delgado F, Prado MJ, Cortina P. Inguinal hernia and certain risk factors. Eur $\mathrm{J}$ Epidemiol. 1992; 8:277-82.

16. Carbonell JF, Sanchez JL, Peris RT, Ivorra JC, Del Baño MJ, Sanchez CS, et al. Risk factors associated with inguinal hernias: A case control study. Eur J Surg. 1993; 159:481-6.

17. ASMA Kabir, M Sharmin, K Akhter, F Akhter, MR Haq, MM Hasan et al. Early Outcome of Lichtenstein Technique for Inguinal Hernia Repair in Tertiary Care Hospital. AKMMC J. 2019; 10(1):62-6.

18. Bhattacharjee PK. Surgical options in inguinal hernia: Which is the best. Indian J Surg. 2006; 68:191-200.

19. McCormack K, Scott NW, Go PM, Ross S, Grant AM. EU Hernia Trialists Collaboration. Laparoscopic techniques versus open techniques for inguinal hernia repair. Cochrane Database Syst Rev. 2003; CD001785.

20. Berthier Nsadi, Olivier Detrt, Willy Arung; Inguinal hernia surgery in developing countries: should laparoscopic repairs be performed?. Pan African Medical Journal. 2017; 27:5. doi:10.11604/pamj. 2017; 27.5.12358. 